\title{
Community variations in infant and child mortality in Peru
}

\author{
BARRY EDMONSTON AND NANCY ANDES \\ From the International Population Program, Cornell University, Ithaca, New York 14853, USA
}

\begin{abstract}
Data from the national Peru Fertility Survey are used to estimate infant and childhood mortality ratios, 1968-77, for 124 Peruvian communities, ranging from small Indian hamlets in the Andes to larger cities on the Pacific coast. Significant mortality variations are found: mortality is inversely related to community population size and is higher in the mountains than in the jungle or coast. Multivariate analysis is then used to assess the influence of community population size, average female education, medical facilities, and altitude on community mortality. Finally, this study concludes that large-scale sample surveys, which include maternal birth history, add useful data for epidemiological studies of childhood mortality.
\end{abstract}

Recent decades have witnessed an important change in our thinking about health and disease. There has been a striking movement toward considering disease within a broader ecological framework and away from describing the treatment of disease solely in terms of technology. Although we need continued work on specific disease processes and on clinical medical treatment, a broader scope of health necessitates a concern with various environmental and family factors, medical facilities and public programmes, and their effect on health. More traditional medical research has tended to emphasise clinical or narrow public interventions-for instance, immunisations; within an ecological framework we require a wholistic concept of the major influences on disease.

Four-general influences on disease may be distinguished. Firstly, there are biological characteristics of the individual, including age, sex, and various genetic characteristics (these are qualities on which neither medical treatment nor public programmes have much effect). Secondly, there are diverse individual characteristics, both voluntary and involuntary, which include smoking and food choices as well as the general context of making these choices. Public programmes to influence personal habits, mainly in the area of education, can and have been tried. Thirdly, there are environmental conditions; the two major components of the environment are the family, which offers a fundamental economic and nutritional context, and the community, which provides a basis for diversity of public services such as housing, water, sanitation, and economic conditions. It is primarily in this area of interest that recently enlarged health programmes have begun to work. Fourthly, and finally, there are direct medical and health interventions that have formed and will continue to be a crucial aspect of individual health.

The research reported here does not offer a complete specification of health determinants but does consider a selected set of variables within the framework outlined. We begin by taking into account known age-sex variations in mortality by developing a standardised mortality ratio. We look at community population size, a measure of family social and economic status (average years of female education), an indicator of specific health interventions (medical facilities in the community), and environmental differences by region and altitude. This research is an exploratory study rather than a test of a set of hypotheses.

The assumption underlying this inquiry is that there exists considerable variation in community mortality, and it is possible to understand partially the broad factors related to these variations. The hope of this research is that it might clarify discussion of what factors can be modified to improve the health of children.

\section{Material and methods}

Data reported in this paper are derived from the household interview and community inventory of the Peru Fertility Survey. The Peru Fertility Survey (PFS) was carried out between July 1977 and June 1978 by the Demography Section, National Statistical Office, under the direction of Mr A Raul 
Garcia. The PFS is associated with an international series of fertility surveys, the World Fertility Survey (WFS). ${ }^{1}$

The PFS was a three-stage area probability sample. The first stage included the selection of 124 primary sampling units (ranging from small rural hamlets to a sample of entire metropolitan Lima). For each of these units, community data are available about its location and medical facilities. The second stage was a systematic selection of 8979 households with probabilities proportional to size in order to achieve random selection with unequal sized clusters. In the third stage interviews were obtained with 5640 ever-married women aged 15-49. These interviews used the standard WFS questionnaire schedule in which women gave a complete retrospective maternal birth history, including each live birth in sequential order, its sex and date of birth, and age at death if dead at the time of the interview. ${ }^{2}$

Comparisons with WFS-associated surveys indicate generally complete coverage of births, as reported by the maternity histories, and that the omission of births is probably low in the PFS. ${ }^{3}$ More important to our concern here is that there is no evidence of omission of infant deaths. The retrospectively reported infant mortality rates for the period $1968-77$ is $102 / 1000$, which is close to 92/1000 reported in the 1978 United Nations Demographic Yearbook. In more intensive checking than can be reported here we have found the mortality data in the PFS to be consistent and generally free of suspected omissions.

The basic data for this study are mortality ratios, by age and sex, for the 124 communities in the PFS. Mortality ratios were calculated to express the community's mortality relative to the Peruvian national average. Firstly, in the national sample all children living during 1968-77 were included in order to calculate by sex: $(a)$ the probability of living from birth to age $1,(b)$ the probability of living from 1 to 5 , and $(c)$ the probability of living to the date of interview. The probabilities for $(a)$ and $(b)$ from the total sample of the PFS data are:

$\begin{array}{ccc} & \text { Birth to age 1 } & \text { Age 1 to age 5 } \\ \text { Boys } & 0.8948 & 0.9362 \\ \text { Girls } & 0.9000 & 0.9437\end{array}$

and the probabilities for $(c)$ include separate figures by sex for each of the 10 years before the survey.

Secondly, in each community all children were aggregated by sex and year of birth. The number actually alive at age 1 , age 5 , and the survey were compared with the number expected to be alive from national probabilities. The actual mortality ratio is defined as:

\section{Live born minus still alive \\ Mortality ratio $=\frac{}{\text { Live born minus expected to be alive }}$}

Two independent variables were specifically constructed for this investigation. Average female education, in mean years of schooling completed for women aged 15-49, for each community is used to reflect family social conditions. To disentangle female education from a moderate correlation with the community's population size, female education is adjusted by expressing it as the number of years a community's mean female education deviates from that predicted from its population size. This measure of adjusted female education separates distinctly general community development, indicated by population size, from particular community variations in female education. Medical facilities in the community are measured by the existence of hospitals, medical clinics, medical centres, dispensaries, pharmacies, and medical posts in the community, ranged in a hierarchy from none or few facilities to many or all facilities (the original checklist of six facilities was used to construct a seven point Guttman scale, ${ }^{4}$ and then adjoining categories were collapsed to form a four point scale). Data on medical facilities were collected from information supplied by the Peruvian Ministry of Health and checked against reports while the interview team was in the community.

\section{Results}

The average mortality ratio for both sexes, from birth to age 10 , is 1.08 for the 124 communities. The ratio ranges from 0 (in one small community no woman reported a death) to $2 \cdot 4$, with a standard deviation of 0.51 . Table 1 shows community variations in mortality. Metropolitan Lima has relatively low mortality overall, less than one-half the nationally expected level. Communities in the coast and jungle (selva) areas are slightly below national levels. Mountain (sierra) communities, comprising about one-half of the total communities, have mortality levels about one-third above the national averages. A strong rural-urban difference in mortality also exists. Predominantly rural communities have relatively high mortality, and urban areas are slightly below the national averages.

Community conditions are reflected by four independent variables: community size, level of female education, provision of medical services, and altitude. Two variables indicate the social aspects of the community: population size and average female education. Altitude of the community is included as an indicator of one of the most important aspects of Peruvian physical ecology. 
Table 1 Mortality ratios for both sexes, birth to age 10 for 124 Peruvian communities

\begin{tabular}{lcll}
\hline Variable & No & Mean & Standard deviation \\
\hline Region: & 1 & 0.45 & \\
Lima & 39 & 0.83 & 0.48 \\
Coast & 64 & 1.29 & 0.49 \\
Mountain & 20 & 0.92 & 0.33 \\
Jungle & & & \\
Residence: & 51 & 1.31 & 0.46 \\
Rural & 73 & 0.91 & 0.49 \\
Urban & 124 & 1.08 & 0.51 \\
Overall & & & \\
\hline
\end{tabular}

We use multiple classification analysis (MCA) for this multivariate analysis. ${ }^{5}$ There are three reasons for using MCA at this point. Firstly, it is important to consider the impact of each independent variable in the case of intercorrelated independent variables. Secondly, MCA does not assume that the effects of independent variables are linear. Thirdly, MCA offers an efficient method of statistical fitting for categorical independent variables. The four independent variables are included in the multiple classification analysis to explain overall mortality from birth to age 10 , mortality for the first year of life, and mortality from age 1 to age 5 .

\section{Mortality for age 0-10}

Table 2 displays other MCA results for mortality for both sexes from birth to age 10. Larger communities generally have lower mortality, but after controlling for other variables, there is no definite association. Population size is not statistically significant at the 0.05 level and, furthermore, shows no progressive influence on mortality.

Adjusted female education, in years of deviations away from the expected value, shows a striking relationship with mortality, even after controlling other variables. Communities with poorly educated women have $20-30 \%$ higher mortality than the national average, and communities with the most educated women have about $40 \%$ lower mortality. It appears that female education-as a general indicator of family economic resources, of formal knowledge, and of ability to gain access to health resources-is thus highly associated with differential community mortality. These data do not suggest the exact linkage of the relationship but confirm that the relationship persists strongly in the presence of other variables that might be thought to diminish it.

The presence of medical facilities, as measured here, does not seem to be a powerful determinant of community mortality. Note especially that the category means display lower mortality when there are more medical facilities, but the adjusted deviations show that this association largely results from the correlation of medical facilities with other variables in the model-that is, medical facilities tend to locate in larger, better educated, lower elevation communities, ${ }^{6}$ which account for much of the effect of medical facilities. Cautions need to be added to this conclusion. Firstly, the medical facilities' variable ascertains the existence of a facility, and not how many children are served or the quality of its service. Secondly, medical facilities are located for specific reasons, such as the size and political demands of the community, as well as because of higher community mortality. So while noting that this spatial analysis fails to show a persuasive influence for medical facilities, it is clear that the variable is poorly favoured in empirical measurement.

Table 2 Multiple classification analysis of mortality, both sexes, from birth to age 10, for 124 Peruvian communities, 1968-72

\begin{tabular}{|c|c|c|c|c|}
\hline $\begin{array}{l}\text { Independent } \\
\text { variable }\end{array}$ & $\begin{array}{l}\text { Sample } \\
\text { size }\end{array}$ & $\begin{array}{l}\text { Category } \\
\text { mean }\end{array}$ & $\begin{array}{l}\text { Unadjusted } \\
\text { deviations }\end{array}$ & $\begin{array}{l}\text { Adjusted } \\
\text { deviations }\end{array}$ \\
\hline \multicolumn{5}{|l|}{ Population size: } \\
\hline$\leqslant 999$ & 28 & $1 \cdot 35$ & 0.27 & -0.03 \\
\hline $1000-2499$ & 23 & $1 \cdot 26$ & 0.18 & 0.09 \\
\hline $2500-9999$ & 27 & 0.94 & -0.14 & -0.06 \\
\hline $10000-24999$ & 22 & 0.92 & -0.16 & 0.08 \\
\hline$\geqslant 25000$ & 24 & 0.90 & -0.18 & -0.05 \\
\hline \multicolumn{5}{|c|}{ Adjusted female education:* } \\
\hline-1.50 & 23 & 1.44 & 0.36 & $0 \cdot 28$ \\
\hline-1.49 to -0.50 & 31 & $1 \cdot 32$ & 0.24 & 0.21 \\
\hline-0.49 to 0.49 & 27 & 0.98 & $-0 \cdot 10$ & -0.11 \\
\hline 0.50 to 1.49 & 17 & 1.02 & -0.06 & -0.00 \\
\hline$\geqslant 1.50$ & 26 & 0.62 & -0.46 & -0.38 \\
\hline \multicolumn{5}{|l|}{ Medical facilities } \\
\hline 1, Few & 35 & $1 \cdot 38$ & 0.30 & $0 \cdot 10$ \\
\hline 2 & 23 & 1.06 & -0.02 & -0.10 \\
\hline 3 & 26 & 0.94 & -0.14 & -0.08 \\
\hline 4, Many & 40 & 0.92 & -0.16 & 0.01 \\
\hline \multicolumn{5}{|l|}{ Altitude (m): } \\
\hline$\leqslant 999$ & 54 & 0.86 & -0.22 & -0.08 \\
\hline 1000-1999 & 10 & $1 \cdot 11$ & 0.03 & -0.08 \\
\hline $2000-2999$ & 15 & $1 \cdot 12$ & 0.04 & -0.05 \\
\hline $3000-3499$ & 27 & $1 \cdot 21$ & 0.13 & 0.05 \\
\hline$\geqslant 3500$ & 18 & 1.49 & 0.41 & 0.26 \\
\hline Grand mean & 124 & 1.08 & - & - \\
\hline Multiple $\mathbf{R}^{2}$ & & & & 0.445 \\
\hline
\end{tabular}

*Statistically significant at the 0.05 level.

Altitude shows slightly lower childhood mortality below $3000 \mathrm{~m}$ and a much higher mortality level for the 18 communities at $3500 \mathrm{~m}$ and over. It is important to emphasise that higher mortality for high altitude communities persists after controlling for other factors. They do not have higher mortality because of small population size or low family resources or absent medical facilities but apparently because of high altitude directly, or some other factor associated with high altitude. 


\section{Infant mortality 0-1}

Table 3 shows variations in mortality, from birth to age 1. They show similar results to those in the previous discussion. Community population size, although not statistically significant, shows a more uniform pattern, suggesting that this variable might be more important in the first year of life. Overall, communities larger than about 2500 residents appear to have slightly lower infant mortality. Adjusted female education continues to show a dominant effect: communities with poorly educated women ( 0.50 years or less the expected amount) have about $20 \%$ higher mortality, while the 26 communities with the most educated women have about $35 \%$ lower mortality. As before, medical facilities show some variations, but they are neither statistically significant nor consistent. Altitude indicates somewhat lower mortality in the highlands at intermediate elevations-higher than the semi-arid coastal and the Amazonian jungle communities-and especially high infant mortality in communities above $3500 \mathrm{~m}$. Once again, these are genuine effects of altitude since they persist after controlling for other variables.

\section{Childhood mortality 1-5}

A third group analysed is mortality variations for children aged 1 to 5 years. Table 4 displays MCA results for this age group. Community population size does not have a statistically significant effect, nor does it show a consistent effect on early childhood mortality. Adjusted female education continues to show its crucial effect, showing perhaps a strong influence on mortality for ages 1 to 5 . A considerable discrepancy exists between communities with poorly educated women and more advantaged women, showing large mortality variations associated with adjusted female education. Medical facilities display the same varied influence, and indicate that the original relationship between medical facilities and early childhood mortality does not persist after controlling for other variables. Altitude shows a distinctive pattern with childhood mortality: communities at lower elevations have lower mortality and all communities located at over $1000 \mathrm{~m}$ have higher mortality. Evidently, the direct effect of altitude and its connection with aspects of Peruvian physical ecology has different effects for infants and young children.

\section{Discussion}

The interpretation of data collected in a multiple purpose survey without a specific focus on community mortality must be treated with some caution. In this paper no specific hypotheses are tested for purposes of drawing rigorous statistical conclusions. Any attempt at interpretation must therefore be tentative and somewhat speculative.

Table 3 Multiple classification analysis of mortality, both sexes, from birth to age 1, for Peruvian communities, 196877

\begin{tabular}{|c|c|c|c|c|}
\hline $\begin{array}{l}\text { Independent } \\
\text { variable }\end{array}$ & $\begin{array}{l}\text { Sample } \\
\text { size }\end{array}$ & $\begin{array}{l}\text { Category } \\
\text { mean }\end{array}$ & $\begin{array}{l}\text { Unadjusted } \\
\text { deviations }\end{array}$ & $\begin{array}{l}\text { Adjusted } \\
\text { deviations }\end{array}$ \\
\hline \multicolumn{5}{|l|}{ Population size: } \\
\hline$\leqslant 999$ & 28 & $1 \cdot 31$ & 0.24 & 0.06 \\
\hline $1000-2499$ & 23 & $1 \cdot 22$ & 0.15 & 0.13 \\
\hline $2500-9999$ & 27 & 0.99 & -0.08 & -0.05 \\
\hline $10000-24999$ & 22 & 0.92 & -0.15 & -0.00 \\
\hline$\geqslant 25000$ & 24 & 0.86 & $-0 \cdot 21$ & $-0 \cdot 13$ \\
\hline \multicolumn{5}{|c|}{ Adjusted female education:* } \\
\hline-1.50 & 23 & $1 \cdot 38$ & $0 \cdot 31$ & $0 \cdot 26$ \\
\hline-1.49 to -0.50 & 31 & $1 \cdot 27$ & 0.20 & $0 \cdot 16$ \\
\hline-0.49 to 0.49 & 27 & 0.97 & $-0 \cdot 10$ & $-0 \cdot 11$ \\
\hline 0.50 to 1.49 & 17 & 1.09 & 0.02 & 0.06 \\
\hline $1 \cdot 50$ & 26 & 0.65 & -0.42 & -0.35 \\
\hline \multicolumn{5}{|l|}{ Medical facilities: } \\
\hline 1, Few & 35 & $1 \cdot 25$ & $0 \cdot 18$ & -0.15 \\
\hline 2 & 23 & 1.09 & 0.02 & -0.05 \\
\hline 3 & 26 & 0.96 & $-0 \cdot 11$ & -0.05 \\
\hline 4, Many & 40 & 0.91 & $-0 \cdot 16$ & $0 \cdot 10$ \\
\hline \multicolumn{5}{|l|}{ Altitude (m):* } \\
\hline$\leqslant 999$ & 54 & 0.91 & $-0 \cdot 16$ & -0.02 \\
\hline $1000-1999$ & 10 & 0.97 & -0.10 & -0.21 \\
\hline $2000-2999$ & 15 & 0.96 & $-0 \cdot 11$ & -0.21 \\
\hline $3000-3499$ & 27 & $1 \cdot 17$ & 0.10 & 0.02 \\
\hline$\geqslant 3500$ & 18 & $1 \cdot 54$ & 0.47 & 0.33 \\
\hline Grand mean & 124 & 1.07 & - & - \\
\hline Multiple $\mathbf{R}^{2}$ & & & & 0.322 \\
\hline
\end{tabular}

*Statistically significant at the 0.05 level.

Table 4 Multiple classification analysis of mortality, both sexes, aged from 1 to 5, for Peruvian communities, 1968-77

\begin{tabular}{|c|c|c|c|c|}
\hline $\begin{array}{l}\text { Independent } \\
\text { variable }\end{array}$ & $\begin{array}{l}\text { Sample } \\
\text { size }\end{array}$ & $\begin{array}{l}\text { Category } \\
\text { mean }\end{array}$ & $\begin{array}{l}\text { Unadjusted } \\
\text { deviations }\end{array}$ & $\begin{array}{l}\text { Adjusted } \\
\text { deviations }\end{array}$ \\
\hline \multicolumn{5}{|l|}{ Population size: } \\
\hline$\leqslant 999$ & 28 & $1 \cdot 32$ & $0 \cdot 30$ & -0.07 \\
\hline $1000-2499$ & 23 & $1 \cdot 39$ & 0.37 & $0 \cdot 18$ \\
\hline $2500-9999$ & 27 & 0.68 & -0.34 & -0.06 \\
\hline $10000-24999$ & 22 & 0.88 & -0.14 & 0.23 \\
\hline$\geqslant 25000$ & 24 & 0.82 & -0.20 & -0.24 \\
\hline \multicolumn{5}{|c|}{ Adjusted female education:* } \\
\hline$-1 \cdot 50$ & 23 & $1 \cdot 33$ & $0 \cdot 31$ & $0 \cdot 14$ \\
\hline-1.49 to -0.50 & 31 & 1.43 & 0.41 & 0.44 \\
\hline-0.49 to 0.49 & 27 & 1.02 & -0.00 & -0.06 \\
\hline 0.50 to 1.49 & 17 & 0.70 & -0.32 & -0.21 \\
\hline 1.50 & 26 & 0.47 & -0.55 & -0.45 \\
\hline \multicolumn{5}{|l|}{ Medical facilities: } \\
\hline 1, Few & 35 & 1.45 & 0.43 & $0 \cdot 14$ \\
\hline 2 & 23 & 1.01 & -0.01 & -0.24 \\
\hline 3 & 26 & 0.56 & -0.46 & -0.40 \\
\hline 4, Many & 40 & 0.96 & -0.06 & $0 \cdot 28$ \\
\hline \multicolumn{5}{|l|}{ Altitude (m):* } \\
\hline$\leqslant 999$ & 54 & 0.63 & -0.39 & -0.27 \\
\hline $1000-2499$ & 10 & $1 \cdot 37$ & 0.35 & 0.26 \\
\hline 2500-9999 & 15 & 1.41 & 0.39 & 0.26 \\
\hline $10000-24999$ & 27 & $1 \cdot 23$ & 0.21 & $0 \cdot 18$ \\
\hline$\geqslant 25000$ & 10 & $1 \cdot 37$ & 0.35 & 0.16 \\
\hline Grand mean & 124 & 1.02 & - & - \\
\hline Multiple $\mathbf{R}^{\mathbf{2}}$ & & & & 0.287 \\
\hline
\end{tabular}

"Statistically significant at the 0.05 level. 
Nevertheless, community mortality data are rare (available statistical studies ${ }^{7}$ report only regional mortality data), the PFS is a valuable source of mortality information, and it is possible to draw some conclusions. The consistent, strong association of average female education and childhood mortality collaborates other research on this topic. Laurell ${ }^{8}$ at the Ciudad Universitaria in Mexico reports that social processes involving economic activities were among the most important conditions for disease in two Mexican villages. Frisancho et $\mathrm{al}^{9}$ document the connection between family socioeconomic status and childhood mortality in an urban Peruvian population. The work reported here indicates that family socioeconomic status is evidently reflected in broad community conditions as well: the social processes that are so significant within the family are also closely connected at the community level. We may thus see that improving the socioeconomic conditions of families decreases general childhood mortality.

We have also seen that there is a varied association between community population size and mortality. It is not a clear, progressive association, and only indicates somewhat lower infant mortality for larger urban areas. The association is not clear because, among other things, community population size does not necessarily imply social development and is not necessarily positive for mortality. Dutt and Baker ${ }^{10}$ in southern Peru, for example, reported that migrants from high altitudes to rapidly growing low-altitude communities exhibit higher morbidity and mortality, even though there is community development. Laurell $^{8}$ found that a more developed Mexican village, with unstable cash crops, actually had higher morbidity than a less developed village with subsistence agriculture. The nature of the social process, therefore, conditions any empirical measure of community development. Health conditions are closely linked to the community development process, but the relationship is intricate. ${ }^{11}$

Finally, we see in this research that altitude has persistent positive relationships with community mortality. This is important since previous research, such as Mazess' ${ }^{12}$ study of neonatal mortality, reports such an association but does not include multivariate analysis. Mazess suggests that mortality at higher altitudes might stem from poorer health facilities or lower family socioeconomic conditions. We see in the results here that higher mortality persists at higher altitudes even after taking these other variables into account. There is thus the strong suggestion that higher mortality may be the direct effect of altitude.

As a final note, this inquiry concludes that traditional demographic surveys may provide a valuable addition to epidemiological information on childhood mortality. There have been relatively few uses of fertility surveys for this purpose ${ }^{13}$ although other researchers ${ }^{14}{ }^{15}$ have also emphasised the need for broader national investigations of an epidemiological nature. With the variety of fertility surveys now on hand, and with the small incremental cost of obtaining community inventory data, this type of epidemiological study promises to be a useful addition to the study of childhood mortality.

We thank Geoffrey Jarvis for his computer programming contributions in developing the basic data sets for this research and Debbie Lucas for preparing the final version of this paper. Roger Avery, Jere Haas, and Frank Young offered useful suggestions on research in progress as well as on earlier drafts of this paper. We naturally accept responsibility for interpretations offered in this paper.

This paper is based on work supported by the US Agency for International Development under grant No AID/w DSPE G-0044.

\section{References}

${ }^{1}$ World Fertility Survey. The world fertility survey: the first three years January 1972-January 1975. London: WFS, 1975.

${ }^{2}$ World Fertility Survey. Core questionnaires. London: WFS, 1975. (Basic documentation No 1.)

${ }^{3}$ Chidambaram VC, Cleland JG, Verma V. Some aspects of WFS data quality: a preliminary assessment. Voorburg, Netherlands: International Statistical Institute, 1980. (Comparative studies No 16.)

${ }^{4}$ Coombs CH, Coombs LC, Lingoes JC. Stochastic cumulative scales. In: Shye SW. Theory construction and data analysis in the behavioral sciences. San Francisco: Jossey-Bass, 1978.

${ }^{5}$ Little R. Linear models for WFS data. Voorburg, Netherlands:International Statistical Institute, 1980. (WFS technical bulletin No 9.)

- World Health Organisation. Sixth report on the world health situation, 1973-1977. Part II: reviews by country and areas. Geneva: World Health Organisation, 1980.

${ }^{7}$ Peru, Instituto Nactional de Estadistica. La mortalidad en los primeros anos de vida, 1967-8. Boletin de Analisis Demografico $1977 ; 17$.

${ }^{8}$ Laurell AC. Disease and rural development: a sociological analysis of morbidity in two Mexican villages. Int J Health Serv 1977; 7: 401-23.

${ }^{9}$ Frisancho AR, Klayman JE, Matos J. Symbiotic relationship of high fertility, high childhood mortality, and socio-economic status in an urban Peruvian population. Hum Biol 1976; 48: 101-11. 
${ }^{10}$ Dutt JS, Baker PT. Environment, migration and health in southern Peru. Soc Sci Med 1978; 12: 29-39.

${ }^{11}$ Weiss-Altaner ER. Produccion de salud y mortalidad. Demografia y Economia 1975, 9: 53-64.

${ }^{12}$ Mazess RB. Neonatal mortality and altitude in Peru. Am J Phys Anthropol 1965; 23: 209-13.

${ }^{13}$ Edmonston B. Population research in Latin America and the Caribbean. Ann Arbor, Michigan: UMI Publications, 1979.
${ }^{14}$ Minchaca FJ. La mortalidad infantil en Latinoamerica. Estadistica 1960; 19: 1-28.

${ }^{15}$ Aguirre A. Algunas bases epidemiologicas de la mortalidad infantil. Revista Colombiana de Obstetricia y Ginecologia 1966; 17: 349-57. 